\title{
EL PERIODISMO EN CHIAPAS DURANTE EL GOBIERNO DE ABSALÓN CASTELLANOS DOMÍNGUEZ
}

Sarelly Martínez Mendoza Universidad Autónoma de Chiapas

\begin{abstract}
RESUMEN
Este trabajo pretende analizar la relación de la prensa con la administración de Absalón Castellanos Domínguez, quien gobernó Chiapas de 1982 a 1988, que se reflejó en un periodismo que ignoró los problemas sociales de la entidad y se multiplicó rápidamente, con una existencia en Tuxtla Gutiérrez de veintinueve diarios. Pero no todo fue tan homogéneo: surgió también un grupo de reporteros, sobre todo corresponsales nacionales, que por vez primera cuestionaron el papel de los gobernantes. Ese es el tema de este artículo, continúa el análisis ya iniciado en "La Prensa Maniatada, el periodismo en Chiapas de 1827 a 1958" (2004), bajo la premisa de que toda publicación puede analizarse desde la perspectiva de la empresa informativa, es decir, recursos materiales: imprentas, papel; recursos humanos: directores, reporteros, periodistas; compradores: lectores, anunciantes; producto informativo: publicaciones, y relaciones externas de la empresa con el poder político y económico.
\end{abstract}




\section{EL GENERAL Y LOS ESCRIBAS}

Ocho días antes de que asumiera el cargo de gobernador, Absalón Castellanos se reunió con periodistas y editores chiapanecos a quienes les confesó: "Desde hace algún tiempo tenía el deseo de reunirme con ustedes, pero hay veces que cuando los veo me dan ganas de salir corriendo" 1 .

La ocurrencia del general fue recibida por los asistentes con una fuerte carcajada y cierto estupor, pues la declaración no dejaba de retratar, aunque fuera muy borrosamente, a la prensa chiapaneca: más temida que respetada e insaciable con los dineros públicos.

Los editores, además, no ocultaban su nerviosismo ante el nuevo trato que pudieran recibir de un militar de tres estrellas, del que se creía que implementaría el orden y la disciplina castrense en la administración pública.

Pero el militar dejó las finanzas en manos de su hijo Ernesto, y la política en las de su secretario particular, Manuel Salinas Solís.

\section{SETENTA Y CINCO PUBLICACIONES}

La curva ascendente de nuevas publicaciones continuó inexorable en una tierra de pocos lectores y muchos comerciantes del periodismo. 
La publicación que dio inicio a la actividad periodística de este sexenio fue La Voz del Sureste — publicado desde 1949, primero como semanario y después como bisemanario—, que en 1983 se convirtió en diario.

Su director, Roberto Coello Trejo, era el único de los editores chiapanecos que, en un concierto de voces sumisas, permitía la apertura y promovía la crítica informativa.

Julio Serrano Castillejos y Roberto Mancilla Herrera utilizaron las páginas de La Voz para expresar sus comentarios que en poco coincidían con la postura oficial.

En ese primer año de gobierno aparecieron en Tuxtla los periódicos El Vate, Hablemos, y En Marcha, mientras que en San Cristóbal de Las Casas vieron la luz el diario Hoy y el semanario El Chiapaneco.

En 1984 fueron fundados en Tuxtla: Chiapas Hoy y La Versión; y en Tapachula: La Opinión, así como Noticias de Chiapas, que aún circula y dirigido desde entonces por Carlos Correa Leo.

El año siguiente continuó la multiplicación de publicaciones: en Yajalón surgió Nueva Generación, de José López Arévalo; en Tapachula, Revista del Sureste, de Mario Ruiz Redondo, y en Tuxtla: Tinta Joven, Seis A.M., la revista Bonampak, Prensa Libre y el semanario Signos. 
Al cuarto año de gobernador, empezaron a circular en Tapachula, Las Últimas Noticias y

El Sur de México; en Tuxtla: Perfil del Sureste, de David Franco Ávila, este marcó el inicio de una nueva forma de hacer periodismo, donde se priorizó la investigación, la crónica, las entrevistas y los reportajes.

En 1987 irrumpieron nuevos periódicos: Sur, Confidencia, Combate, Marcha y Caretas, redactado este último en el penal de Cerro Hueco por Jorge Enrique Hernández Aguilar, un periodista preso en esos momentos por obstruir las vías federales de comunicación en demanda de mejores condiciones para los campesinos.

En el último año de gobierno de Absalón Castellanos nacieron El Observador de la Frontera Sur, la revista Impactos, Perfil y Eco, en la capital del estado; El Mundo, que fue el primer diario de Comitán, y El Sur de Chiapas, en San Cristóbal.

Los periódicos fundados en este sexenio, más los que habían sobrevivido de años anteriores, arrojaban una cifra de setenta y cinco publicaciones existentes en Chiapas, las cuales vivían, en su mayoría, de la publicidad oficial y estaban concentradas en Tuxtla Gutiérrez. $^{2}$

Para observadores perspicaces como Julio Serrano la multiplicación de publicaciones solo podía convenirle al propio gobierno, porque atomizaba la opinión pública:

En no pocas ocasiones se le llamó "Cuarto Poder" a un dragón de diecisiete desorientadas cabezas ${ }^{3}$ que, de existir la unión de las mismas, tendría fuerza y efectividad que intrínsecamente le 
pertenece. Como la mayoría de dueños de dichos órganos informativos trabaja bajo la convicción de poseer el mejor periódico, casi nadie le concede importancia a la unión de un gremio, que al igual que el espray, disemina sus esfuerzos y sus acciones se las lleva el viento. Los políticos ven con agrado la situación prevaleciente y hasta la propician, pues comprenden que es preferible aguantar piquetes de hormigas y no las zarpas de un tigre (La Voz del Sureste, 7 de diciembre de 1985).

La sobreabundancia de periódicos también se debió al negocio que representaba no solo para los editores, sino también para los jefes de prensa, quienes exigían hasta cincuenta por ciento del monto de la publicidad que otorgaban.

\section{PRENSAS DE PLOMO}

Los cortos tirajes de los periódicos chiapanecos, con un promedio de trescientos ejemplares, permitían que las ediciones se imprimieran en prensa plana sin problema alguno.

Las redacciones eran ruidosas, sucias, impregnadas de tinta y grasa, donde la vida empezaba por las noches, con la llegada del linotipista, el técnico en impresión y el ayudante.

De las publicaciones que se editaron en esta etapa, solo La República en Chiapas y el Número Uno contaron con off-set. ${ }^{4}$ 
La respuesta para no cambiar de maquinaria la dio Francisco Núñez López, director de El Sol de Chiapas: "Para qué voy a introducir maquinaria moderna en mi taller, si con lo que poseo ahora me basta para editar el periódico. No tiene sentido hacer una fuerte inversión para obtener la misma utilidad que se logra con el sistema caliente" (García Mendoza 1986: 22).

Ese era el sentir general de los editores de periódicos: la prensa plana cubría sus necesidades de sacar trescientos ejemplares diarios y, en casos extraordinarios, quinientos, que ya era una cantidad fabulosa, especialmente para los informativos tuxtlecos.

\section{LOS ESPACIOS PUBLICITARIOS}

Los periódicos tapachultecos eran los únicos que podían alardear de un gran número de anunciantes, estos alcanzaban a cubrir cincuenta por ciento de la superficie total del ejemplar.

Distinto a lo que sucedía con los periódicos de Tuxtla o de San Cristóbal, los de Tapachula vendían todos los espacios, y no era raro que la información en primera plana quedara minimizada por la publicidad comercial.

La lejanía de la capital chiapaneca pudo haber empujado a los dueños de periódicos de esta ciudad fronteriza a buscar formas de financiamiento ajenas al gobierno estatal. 
Encontraron el apoyo de los comerciantes locales, especialmente de los concesionarios o dueños de los negocios Rialfer, Hotel Loma Real, Superior, Korsa, Automotriz del Soconusco, Cines Maya, El Alambre de Oro, Casa Guerson y La Joya.

La inflación provocó que se disparara el precio de la publicidad, de veinte mil pesos la plana a principios del sexenio, al final se cotizaría en ciento treinta mil pesos.

Algo similar ocurrió con el precio de los periódicos, costaban quince pesos a finales de 1982, y cuatrocientos en diciembre de 1988.

En 1983, cuando los periódicos locales se adquirían en veinte pesos promedio, un periodista tuxtleco se lamentaba de que, para estar medianamente informado, se tenían que adquirir publicaciones nacionales que costaban tres o cuatro veces más: por ejemplo, Proceso se vendía en noventa pesos; Excélsior en ochenta, treinta pesos más que en el Distrito Federal; Selecciones en ciento noventa, e Impacto y Siempre!, sesenta pesos cada una. Para un empleado, que percibía en promedio trescientos ochenta pesos diarios, era prácticamente imposible adquirirlos y mucho más para los reporteros, que no tenían un sueldo fijo (La Voz del Sureste, 5 de enero de 1984). ${ }^{5}$

\section{CLASE POLÍTICA, CLASE LECTORA}

¿Quiénes eran los lectores de la prensa chiapaneca y, sobre todo, de la tuxtleca? Esa era la gran incógnita que intentaron responder algunos periodistas y políticos. 
Patrocinio González Garrido, siendo candidato a la gobernatura por el PRI, dijo que no le extrañaba tanto que se publicaran injurias contra cualquier persona, y a ocho columnas, pero sí que hubiera lectores que lo festinaran y se regocijaran con esas diatribas.

El columnista Julio Serrano Castillejos, quien vivía de actividades ajenas al periodismo, le contestó que, curiosamente, en Chiapas los periódicos no estaban destinados a los gobernados, sino a los gobernantes:

El periodismo a la usanza local no requiere de miles y miles de ejemplares, considerando que lo integran doscientos cincuenta altos y medianos funcionarios con oficinas en Tuxtla Gutiérrez y un tanto igual, del sector público de la ciudad de México, que es su público lector.

Es tan poco el interés del grueso de la población respecto al periodismo local, que el autor de esta parrafada en más de una docena de ocasiones sus amigos y parientes —aclaro, ajenos a la política - le han preguntado si es cierto que de vez en cuando echa el gato a retozar en las páginas de los diarios chiapanecos. ¡Bueno!, el columnista tiene más de cien artículos relacionados con el tema de la destrucción de las selvas de nuestra entidad, escritos y publicados en el lapso de los últimos cinco años en diez o más periódicos de Tuxtla y de Tapachula, pero a pesar de ello no faltan conocidos y amigos que le propongan trate en sus colaboraciones periódicas dicha temática, “aunque sea de vez en cuando" (La Voz del Sureste, 3 de junio de 1988).

Los funcionarios, sin embargo, adquirían los periódicos de manera selectiva: solo aquellos donde se había hablado bien de ellos, aun cuando existieran notas críticas, había siempre personas solícitas a entregarles el diario. 
En una ocasión, conversaban los políticos Romeo Ruiz Armento y Rafael González

Bruno con el periodista Julio Serrano Castillejos; este comentó que Antelmo Esquinca,

Luzán, había dedicado al primero una columna de elogiosos comentarios:

— ¿Caray!, hermano —respondió Romeo—, si yo debiese estar atento a lo que de mi persona se pueda o no decir en los periódicos de Tuxtla, no me alcanzaría mi sueldo para comprarlos todos.

No era necesario, sin embargo, que los funcionarios adquirieran todos los periódicos, pues la encomienda de los distribuidores era que depositaran los ejemplares en las oficinas gubernamentales, ya que estaban escritos para la clase política.

\section{EL PROTAGONISMO DE LOS COORDINADORES DE COMUNICACIÓN SOCIAL}

Nunca antes los coordinadores de comunicación, jefes de prensa o de difusión, habían tenido una actuación tan protagónica como la que jugaron en el sexenio de Absalón Castellanos Domínguez. Y había razones para ello: tres habían tenido una participación destacada en el periodismo nacional: Armando Arévalo Macías, Isabel Arvide y Daniel Flores Meneses.

Eran personajes, y en ese sentido, recibieron la confianza de controlar la publicidad, de repartir subvenciones y abultar el presupuesto destinado a la prensa. 
Los anteriores jefes de prensa habían tenido una participación discreta en la relación prensa y Estado, y se habían concretado a dirigir algún periódico oficial, elaborar boletines, difundir información turística de Chiapas o acompañar en sus giras al gobernador.

Por ejemplo, Julio Farías, el primer encargado de estas funciones que recibió el nombramiento de jefe del departamento de prensa y turismo en el gobierno de Rafael Pascacio Gamboa, tuvo como responsabilidad dirigir Chiapas Nuevo, una publicación oficial emblemática de los cuarenta, donde colaboraban los mejores periodistas de la época.

Armando Duvalier, poeta, y Jesús Agripino Gutiérrez, escritor, los dos siguientes jefes de prensa, entendieron que su tarea estaba más en el terreno de la cultura, y fueron factores importantes en el despertar artístico de Chiapas de principios de los cincuenta, que alcanzó la cima con el nacimiento del Ateneo.

Carlos Ruiseñor Esquinca, director general de información y prensa con Efraín Aranda Osorio, tuvo un papel marginal en las distribuciones de publicidad y dinero que realizó el gobernador para los editores chiapanecos.

Humberto Gallegos Sobrino fue jefe de prensa con cuatro gobernadores, desempeñando su encargo discretamente y hasta distante de sus responsabilidades de difusión de la obra gubernamental. Lo hacía, mayormente, en sus columnas periodísticas — que no dejó de 
escribir — desde que inició con el gobierno de Samuel León Brindis, a quien le siguieron

José Castillo Tielemans, Jorge de la Vega Domínguez y Salomón González Blanco.

Los voceros de Manuel Velasco Suárez: Bernardo Meneses Curling, Jesús Domínguez Gil, Milton Hernández Moguel y Carlos Ruiseñor Esquinca; tuvieron que plegarse al carácter hosco del gobernador, y acataron la decisión de otorgar solo lo indispensable de publicidad a los periódicos chiapanecos.

Juan Sabines, por su parte, dejó en manos de su amigo Francisco Núñez López, dueño de El Sol de Chiapas, la relación de su gobierno con la prensa, pero fueron su hijo Carlos, secretario de finanzas, Antonio Pariente Algarín, y él mismo, quienes otorgaron los apoyos a los periodistas.

En un principio, Absalón Castellanos Domínguez decidió que fuera el jefe de prensa quien diera los apoyos económicos a los periodistas: Armando Arévalo Macías, quien recién nombrado coordinador de comunicación social se sorprendió cuando el tesorero de gobierno del estado le entregó un maletín lleno de dinero, que iría —le dijeron—al rubro de gastos sin comprobar.

El veterano comunicador, ex jefe de prensa de la SEP y ex reportero del Novedades de México, se rehusó a dar el dinero directamente a los informadores, e intentó transparentar el apoyo del gobierno a los medios a través de la publicación de noticias y desplegados oficiales. 
Pero los editores, acostumbrados a recibir moneda en efectivo, sin mediar facturas, presionaron al gobierno para el restablecimiento de los antiguos privilegios.

"Era muy difícil encausar a los periodistas a una relación transparente con el gobierno estatal. Recuerdo que la primera visita que recibí fue la de un editor quien me exigió viáticos y seis boletos de avión a la ciudad de México, porque viajaría con toda su familia. Juan Sabines los había acostumbrado a sangrar y a vivir del erario", señala Armando Arévalo (entrevista, 15 de enero de 2006).

Ante la falta de voluntad de entregar subvenciones, emergieron, entonces, el secretario general de gobierno, Javier Coello Trejo, y el secretario particular del gobernador, Manuel Salinas, para tratar directamente con los periodistas bajo ese tenor. Esto trajo como consecuencia el que los informadores pidieran instrucciones de tales personajes, y no de Arévalo Macías. El coordinador de comunicación social, al verse marginado de sus actividades, prefirió renunciar.

El 15 de junio de 1981, al marcharse de Tuxtla, fue despedido por el gobernador quien le reiteró su amistad, además, en muestra de agradecimiento, le llenó las bolsas de su camisa y su pantalón con dinero. Total, para eso era el gobernador, para repartir billetes, le dijo. 
El sustituto de Armando Arévalo fue Daniel Flores Meneses, un joven reportero del noticiario más importante de la televisión nacional, 24 Horas de Televisa, conducido por Jacobo Zabludowski.

Su primera acción en el gobierno del estado fue cambiar de nombre a la Dirección de Comunicación Social por la Dirección de Información, Radio y Televisión, con lo que dio mayor relevancia a los medios electrónicos.

Y de hecho lo tuvieron: si la prensa había sido ineficaz para informar a la sociedad, la radio había tomado la responsabilidad de dar a conocer las giras del gobernador, los discursos y, sobre todo, las notas rojas.

La televisión local, que había empezado a dar sus primeros pasos en Chiapas, fue el medio que utilizó Daniel Flores Meneses para hacer su tarea de comunicación: contrató reporteros, técnicos en imagen, camarógrafos, rediseñó los contenidos y buscó un horario adecuado para transmitir un noticiario, que condujo con Martha Grajales.

El noticiario, bautizado con el nombre de "Chiapas Hoy", fue una gran novedad y un éxito entre los televidentes chiapanecos.

Con los medios impresos, Flores Meneses entregó publicidad casi de manera indiscriminada. 
Cuando José López Arévalo lo visitó con el fin de solicitarle publicidad para su periódico Nueva Generación, que se editaba en Yajalón, el funcionario le preguntó sobre el espacio que deseaba destinar a la promoción de la obra de gobierno.

Tímido, el periodista le contestó que lo que él quisiera. "Si quieres, te compro todo el periódico", repuso sonriente Flores Meneses. Y si bien no adquirió las ocho páginas de Nueva Generación, su respuesta indicaba el poder económico y el control político que ejercía el gobierno estatal en los medios de difusión.

"Los periódicos — señala Flores Meneses— no vivían de la publicidad comercial, sino del gobierno. Y cobraban todas las líneas ágatas y los cuadratines, porque así se les había acostumbrado, y si no se les apoyaba, intentaban crear problemas antes de desaparecer" (entrevista, 14 de noviembre de 2005).

Después de la partida del creador de Chiapas Hoy, quien trabajó para el gobierno estatal de junio de 1983 a mayo de 1985, el Sistema Chiapaneco de Televisión, que él había ayudado a crecer, empezó a decaer.

Mario Ruiz Redondo, el nuevo jefe de prensa del gobierno estatal, estuvo al frente de la Coordinación General de Comunicación Social —ahora con este nombre— escasamente doce meses. A su renuncia, por desavenencias con el hombre fuerte del régimen, Manuel Salinas Solís, le seguió la de Martín Martínez Olvera, director de televisión; también Eduardo Moreno Castellanos, quien atendía a corresponsales nacionales y extranjeros; se 
sumó Adriana Zenteno Fernández de radio; Fernando Mendizábal Rico, prensa, y Oswaldo Arrazate Mazariegos, director del área administrativa.

De julio de 1986 a enero de 1988, se hizo cargo de Comunicación Social Miguel González Alonso, periodista sancristobalense, quien previamente se había desempeñado como director de Talleres Gráficos del Gobierno del Estado.

Su gestión, en ese tren de pago de elogios, no podía ser diferente a la de sus predecesores. El contexto social y viciado de los periodistas prácticamente obligaba a los coordinadores a actuar dentro de esos cánones.

Eugenio Berdejo Pinto fue el único que, por su fugacidad en el puesto, que desempeño del 10 al 24 de febrero de 1988, no desplegó sus habilidades de negociador con la prensa chiapaneca.

Si alguien pensó que Isabel Arvide, la coordinadora de Comunicación Social de Absalón Castellanos de marzo a noviembre de 1988, se entraría a una etapa de racionalidad del gasto público, se había equivocado.

La nueva funcionaria multiplicó los gastos en los medios, pagó publicidad oficial, patrocinó reuniones de periodistas, creó premios de literatura y periodismo con cifras que sobrepasaban a las que se otorgaban en el Distrito Federal. ${ }^{6}$ 
Su protagonismo no tuvo parangón con sus antecesores: "El propio general fue víctima de las arrebatadas poses y frases de la Arvide — comenta Carlos Ruiseñor (1994: 306)—, que muy pronto se impuso sobre los principales funcionarios, dictando órdenes y autorizando presupuestos, pagos e inversiones, justificando su acción con el hecho de 'promover' la imagen del gobernador en los últimos meses de su gestión”.

Los coordinadores de comunicación social, a excepción de Armando Arévalo Macías y Eugenio Berdejo Pinto, ejercieron un poder ilimitado: gastaron el presupuesto público y lo otorgaron sin discriminación alguna, con el propósito de que el general tuviera buena prensa.

Por eso era casi imposible publicar notas críticas: “En dónde están los periodistas con agallas para formular comentarios alrededor de la cacareada renovación del PRI y de su democratización interna?", se preguntaba Julio Serrano Castillejos. Y él mismo se respondía: "Aunque la temática es rica en consecuencias sociales y políticas, pocos, muy pocos, nos atrevemos a tocarla, como resultado de que muy pocos, también, estamos apartados de las nóminas del erario" (La Voz del Sureste, 28 de junio de 1986).

Y quienes no trabajaban para el gobierno del estado, dependían de los apoyos económicos otorgados por los funcionarios. 


\section{GANANCIAS COMPARTIDAS}

Los editores chiapanecos tenían por costumbre no pagar salarios a sus colaboradores; por el contrario, esperaban compartir las "ganancias", producto de la venta de notas y de elogios.

Carlos Acevedo Martínez, recién iniciado en el periodismo de los ochenta, no comprendió de inmediato esta práctica tan antigua entre los directores de periódicos chiapanecos.

Al pasar a recoger su credencial en el periódico Últimas Noticias del Ahuizote, su director le saludó diciendo que con aquella identificación y la forma en que escribía iba a "levantar" el billete que quisiera, "pero, ya sabe —le aclaró—, vamos en partes iguales".

Azorado, el novato columnista solo pudo responder con un ¿cómo!, y después, repuesto de la sorpresa, con la negativa de aceptar la credencial bajo esas condiciones (Carlos Acevedo, entrevista 1 de febrero de 2006).

Julio Serrano Castillejos abundó sobre esta situación:

Gran número de directores y dueños de órganos de la información omiten el pago de salarios, emolumentos u honorarios a los columnistas y comentaristas, porque parte de la base, no siempre cierta, de que este tipo de colaborador se agenciará ingresos con el manejo inteligente de sus notas. Valga la comparación: a cierto tipo de periodistas le acontece lo que a los meseros, que al no 
recibir sueldo, viven de las dádivas de las personas que por ellos se hacen servir; misma razón por la cual no consideran necesario los dueños de las negociaciones pagar un salario. Y así, el círculo vicioso se convierte en banda sinfín (La Voz del Sureste, 13 de noviembre de 1984).

Los funcionarios, aprovechando esas circunstancias, establecieron un sistema de apoyos económicos mensuales a los reporteros, columnistas y editores. Isabel Arvide llegó al extremo de obligarlos a hacer fila, para que recibieran un sobre con dinero. Por supuesto, que ganaban más quienes escribían para medios de mayor presencia.

\begin{abstract}
En cuanto al chayo o embute, estaba institucionalizado. Pero no era una desgracia de Chiapas, era una desgracia nacional. El sistema político mexicano, el sistema priísta, lo había implementado, y lo hizo de tal manera que los medios nunca te pagaban bien porque te daban fuentes, y en las fuentes tenías chayo. Había fuentes que tenían muchas derivaciones. Por ejemplo, si tú cubrías médicas: cobrabas en el ISSSTE, en el Seguro, en el Hospital General, porque todos tenían directores de prensa y presupuesto; si cubrías la iniciativa privada, cobrabas en Canacintra, Canaco, Concanaco y Concamín; si cubrías las obreras, bueno, pues ya sabes, cobrabas en todos los sindicatos. Además, en esa época, cada que venía el presidente, se repartía chayo entre los enviados, corresponsales y reporteros (Flores Meneses, entrevista, 14 de noviembre de 2005).
\end{abstract}

Escribir en un periódico, si no se contaba con otro empleo, suponía que se tenía que vivir de las mesadas que, a la luz del día, entregaba el gobierno estatal. El caso de los trabajadores de Número Uno era excepcional, pues habían logrado conformar un sindicato, que obligó a su accionista mayoritario a otorgarles salarios y prestaciones sociales conforme a derecho. 
En la creación de este sindicato se entremezclaron motivos políticos: Eduardo Robledo Rincón, entonces secretario de gobierno, protegió a los trabajadores, debido a su enfrentamiento con el dueño de Número Uno, Jaime Fernández Armendáriz.

\section{LA PIRÁMIDE DE PERIODISTAS}

Los periodistas de los ochenta estaban claramente diferenciados. La cúspide de la pirámide la ocupaban los editores; en el medio estaban los columnistas y los corresponsales nacionales, y en la parte de abajo los reporteros.

Entre los editores también había jerarquías: El primer círculo lo conformaban los dueños de los diarios de Tuxtla Gutiérrez, el segundo los directores de periódicos de Tapachula. A los primeros, por su cercanía geográfica con el gobernador, les era más fácil establecer relaciones políticas con los funcionarios, esto se traducía en publicidad oficial y beneficios colaterales a la actividad periodística.

Los columnistas, hábiles en prodigar elogios y en convertirse en mensajeros de políticos, ejercían un poder solo limitado por sus directores de periódicos; eran expertos en manejar un código cifrado únicamente descifrado por los remitentes y destinatarios, que convertía a la columna en el producto de mayor consumo, no solo para refocilarse en el dolor ajeno, también para llevar la cuenta alegre de los adjetivos laudatorios propios. 
Los corresponsales de medios nacionales hacían su propia composición de las informaciones locales. Los políticos — sensibles, como todos los de su clase, a lo que pudiera decirse de ellos en el Distrito Federal—, reservaban sus exclusivas a los corresponsales. "Pensaban —había señalado Kyra Núñez en un artículo publicado en El Sol de Chiapas el 2 de junio de 1982 — que ninguno de las casi dos docenas de periódicos tuxtlecos" tenía la cobertura suficiente en el estado, por lo que buscaban instrumentos de resonancia en el centro del país. Esas noticias y entrevistas en los medios nacionales se convertían en planas de publicidad, donde los corresponsales tenían el derecho de adjudicarse una comisión entre quince y treinta por ciento.

\section{ELOGIOS Y CALUMNIAS}

La prensa se movía entre el elogio y la calumnia. Era una receta, tan elemental, que fácilmente copiaban los novatos del periodismo, editores, columnistas y reporteros.

El primer paso era el elogio, continuaban las amenazas y finalmente aparecía la calumnia. Cuando Isabel Arvide suspendió la publicidad en un diario tapachulteco, la respuesta fue la difamación. ${ }^{7}$

Patrocinio González Garrido, quien era candidato a la gobernatura por el Partido Revolucionario Institucional, criticó los ataques al considerar que al amparo de la libertad de expresión se caía en la ruindad y la bajeza: "Esto hace que se prostituya el uso de los derechos fundamentales del ser humano en manos de gente que por pasión, por 
incapacidad o por vocación mercenaria, arremete a través de un medio que debe ser limpio y digno" (La Voz del Sureste, 21 de mayo de 1988).

Jaime Fernández Armendáriz, dueño de Número Uno, quiso obtener beneficios económicos inmediatos de su publicación, por lo que pidió al director de su periódico, Romeo Ortega López, que imitara a sus colegas: "Que publicara elogios, y que al día siguiente se acercara a los funcionarios para cobrárselos" (Ortega López, entrevista, 28 de febrero de 2006).

Ensayar otra estrategia era muy complicado en una entidad en donde el elogio y la calumnia habían dado buenos resultados. Cuando el elogio, decíamos, no rendía dividendos económicos, se recurría a la difamación.

Era el último recurso y el más inseguro porque no siempre el difamado buscaba una solución monetaria: a veces interponía alguna demanda o, en otras ocasiones, arreglaba el asunto con su propia mano.

En ambos casos, la reacción de la prensa era unánime: juicio público al funcionario o ciudadano, y solidaridad con el periodista "ofendido" o "injustamente reprimido".

Desde luego que el periodista escogía perfectamente a su víctima: funcionarios menores -presidentes municipales-, dirigentes de organizaciones sociales o campesinas, diputados y ciudadanos comunes. 
Los presidentes municipales, dueños de una parcela y de policías, detenían, a veces, al difamador, incluso a los voceadores que, en un coche equipado con sonido, aireaban las infamias (La Tribuna, 4 de noviembre de 1983; Diario del Sur, 20-24 de marzo de 1986).

Los agentes de migración y comandantes de policía, cuando eran criticados, con razón o no, encomendaban a sus subalternos la detención de los periodistas, incluso en las propias oficinas del periódico, como sucedió en El Sur de México, El Informador y Diario del Sur. $^{8}$

Hubo funcionarios que prefirieron hacer públicas las amenazas y solicitudes de dinero de los periodistas, o bien presentar demanda pena contra los difamadores.

El director de seguridad pública municipal de Tuxtla Gutiérrez, Antonio López Rodríguez, denunció que al asumir el cargo encontró que en su corporación estaban dados de alta periodistas como policías, por lo que procedió a pedirles su renuncia: "Uno de ellos, sin embargo, se presentó a solicitarme su reinstalación o en su defecto que tenía que entregarle cantidades de dinero ya que su director del periódico se lo exigía para poder seguir escribiendo en su diario". Debido a que no satisfizo tal solicitud, agregó, fue difamado por el periodista que cobraba como policía (La Tribuna, 17 de agosto de 1986). 
Manuel Salinas Solís, secretario particular del gobernador, después de una demanda por difamación, logró que Conrado de la Cruz, director de Cuarto Poder, pisara la cárcel y estuviera preso un día en el penal de Cerro Hueco.

No era raro que, ante un sistema jurídico obsoleto, los ciudadanos tomaran venganza de las mentiras periodísticas: Gustavo Méndez, locutor de XEVV, fue vejado por asociados de la Cooperativa Tuxtla, en respuesta por haberlos culpado de un accidente (La Voz del Sureste, 11 de agosto de 1984), y Daniel Flores Meneses, director de la televisión estatal, fue perseguido y golpeado por una turba de profesores, quienes le reclamaban objetividad ante el tratamiento del paro magisterial (La Voz del Sureste, 16 de marzo de 1985).

Roberto Mancilla, una voz crítica en medio del centenar de voces acalladas, preguntó ante tales hechos:

¿Cuál agresión es más grande, ofensiva, siniestra y funesta: la de un señor de la televisión que utiliza este medio para difundir su propia opinión, negando toda posibilidad de mantener una actitud imparcial, como función periodística, o la de un señor locutor que, en uso y abuso de un micrófono, calumnia, difama, arremete brutalmente a quienes merecen tratos de lo que son: mujeres que trabajan en la educación y no en la venta de su cuerpo? Insisto ¿quién arremete más? ¿Los maestros que nunca hicieron justicia por su propia mano? ¿O quienes respaldados por la fuerza de los medios de comunicación dicen y repiten como loros lo que sus patrones les señalan? Esta no es tarea, todos sabemos la respuesta (La Voz del Sureste, 17 de marzo de 1985). 
En 1986, miembros de la Unión Estatal de Productores de Maíz descargaron su furia en contra del corresponsal de Excélsior, Porfirio Díaz López, por considerar que servía a los intereses del gobierno estatal (La República en Chiapas, 15 de mayo de 1986).

En general, durante este sexenio, los reporteros, columnistas y editores gozaron de libertad absoluta para criticar las acciones oficiales, pero en su mayoría prefirieron la autocensura, porque era más redituable en el plano económico.

Fueron éstos años tranquilos, nublados solo por el asesinato de Ronay González Reyes, cometido en las oficinas del periódico El Mundo, de Comitán. De acuerdo con las investigaciones realizadas por la Procuraduría General de Justicia, a cargo de Marco Antonio Besares Escobar, el móvil del crimen fue la venganza. Años atrás el periodista había dado muerte a una persona en el municipio de Villaflores.

\section{CONCURSO DE PANEGÍRICOS}

No había nada tan gastado como los discursos del día de la libertad de expresión. Los gobernantes recordaban a Zarco, a Juárez, y, por supuesto, a Belisario Domínguez, abuelo del gobernante en turno. Era un concurso de aplausos y de panegíricos: los periodistas agradecían el apoyo del gobernador y lo llenaban de elogios.

Absalón Castellanos Domínguez asistió, como gobernador, a la primera celebración de este día el 7 de junio de 1983 en el Salón azul y plata del Hotel Bonampak. Ahí ponderó 
el trabajo "trascendental" para Chiapas de los directores de periódicos, empresarios de la radio, locutores y reporteros:

Ustedes, los periodistas chiapanecos, conocen bien el rumbo y lo han sabido caminar durante años.

Saben el papel vital que juegan, porque conocen su quehacer trascendente.

Exigen respeto, porque se respetan y saben respetar.

Hacen ejercicio de la crítica, porque también la admiten para sí.

Señalan y piden castigo para la inmoralidad, porque también la rechazan y condenan como práctica profesional.

Reconocen su espacio y contribuyen a ensanchar el espacio de los demás, que no es otro que el espacio de la sociedad.

A ese periodismo que se hace en Chiapas, bajo condiciones difíciles, materiales y técnicas, como todo el periodismo que se hace en provincia, para él, para ustedes, mi homenaje, mi reconocimiento y mi plena solidaridad.

Los editores, con esas palabras elogiosas del mandatario, tenían ya preparadas sus ocho columnas, que sintetizadas quedarían como: "En Chiapas, hay libertad de expresión”. Sin más.

Las palabras de Absalón Castellanos no dejaban de ser "idealistas", porque la "cruda realidad de nuestro periodismo habla otro idioma", comentó ese mismo día Carlos 
Ruiseñor Esquinca, galardonado con el premio de periodismo en su modalidad escrita, quien culpaba a los jóvenes de la desastrosa situación de la prensa chiapaneca.

Kyra Núñez, desde El Sol de Chiapas (8 de junio de 1983), le respondió que no eran los jóvenes los autores de esa prensa, tipo "Casa de bolsa", sino las viejas generaciones, que con muy honrosas excepciones, estaban legando un nefasto historial.

Lo cierto era que tanto jóvenes como viejos informadores habían contribuido a crear un modelo de comunicador alejado de los intereses de la sociedad, dicho modelo alcanzó su expresión máxima en estos años.

El premio de periodismo en radio fue para Augusto Solórzano y Rodolfo García del Pino, lo cual disgustó enormemente a este último, porque consideraba que tenía todos los méritos para habérsele otorgado el reconocimiento de manera única.

En 1984, el gobernador decidió multiplicar los premios de periodismo para que nadie quedara fuera de la fiesta. De dos premios se pasó a diez, a quienes, aparte de diploma, se les entregaban cincuenta mil pesos a cada uno, en una ceremonia que tuvo lugar en el salón Montecarlo del hotel Flamboyant, de Tuxtla Gutiérrez.

Al entregar los premios, el gobernador señaló que la libertad de expresión en Chiapas no solo era invulnerable sino indispensable para la vida colectiva, al tiempo que condenaba el asesinato de Manuel Buendía, cometido unos días antes en la ciudad de México: 
Nos duelen y nos lastiman esos hechos, pero no nos hacen perder la convicción y la confianza de que si bien las balas a veces terminan con la vida humana, nunca han sido capaces de acallar el juicio crítico y la voz valiente, y son los adversarios que creen que en la violencia, en el terror y en homicidio, está la clave para disolver, para estrujar y para hacer retroceder la sólida condición de unidad que los mexicanos queremos y debemos tener, para salir de nuestros sobresaltos y vencer nuestros retos.

En 1985, el festejo de la libertad de expresión se realizó en el Centro de Convenciones El Carmen en San Cristóbal de Las Casas, donde el gobernador entregó los premios de periodismo.

El gobernador, conciente ya del verdadero papel de los medios chiapanecos, pidió a los editores que si bien no se podía hacer un periodismo "quijotesco" tampoco hicieran "un periodismo de mercaderes", porque se hacía evidente, incluso para el mismo mandatario, que la prensa chiapaneca era banal y mercantil.

José Villanueva, quien habló a nombre de los galardonados, destacó que el gobernador Castellanos era respetuoso y defensor de la libertad de expresión, y que nunca antes el ejercicio de la libertad de expresión se había dado sin límites, incluso se había caído en el abuso.

Roberto Mancilla criticó sin recelo la entrega de los premios, porque era "fiel reflejo del nivel de concientización” que vivía la sociedad chiapaneca, dijo, y los discursos, 
plagados de una inmensa verborrea se habían repetido hasta el vacío (La Voz del Sureste,

7 de junio de 1985).

Un reducido grupo de periodistas chiapanecos, agrupados en la naciente Unión de Periodistas Democráticos, decidieron — por vez primera en la historia de Chiapasmarchar ese mismo día en protesta por las agresiones cometidas en contra de sus miembros y por la muerte de Manuel Buendía Tellezgirón.

Para la celebración del día de la libertad de expresión de 1986, el festejo se trasladó a Comitán, donde se premió a los periodistas locales en la Casa de la cultura. Ahí el gobernador, con la autocomplacencia de siempre, les dijo que la libertad de expresión tenía vigencia en Chiapas: "Lo saben quienes escriben y lo saben también los lectores".

Pero no solo los periodistas resultaron galardonados, también los hombres del poder. Al gobernador se le entregó una medalla de reconocimiento; a su esposa, Elsy Herrerías, una charola de plata, y al coordinador de comunicación social, Mario Ruiz Redondo, una pluma de oro. El motivo: "Haber impulsado la libertad de expresión".

El obispo Samuel Ruiz García, el panista Valdemar Antonio Rojas López y el director de Tiempo de San Cristóbal, Amado Avendaño Figueroa, intentaron festejar el día de la libertad de expresión en el penal de Cerro Hueco — donde estaba preso el periodista Jorge Enrique Hernández Aguilar-, pero se lo impidieron las autoridades del centro penitenciario. 
Aun así, el dirigente panista alcanzó a criticar la perversa relación que se había establecido entre los periodistas y los políticos: "No es posible hablar de libertad de expresión cuando la mayor parte de las publicaciones y de los comunicadores reciben dinero del gobierno, a tal grado que cuando les suspenden el subsidio, tienen que arrodillarse y plegarse a los lineamientos oficiales" (La Voz del Sureste, 8 de junio de 1986).

El ambiente general, sin embargo, era de complacencia hacia los funcionarios, y se veía con molestia a quienes se atrevían a cuestionar la relación entre prensa y Estado, aun cuando algunos, como Julio Serrano Castillejos, indicaran que el progreso del país requería del ejercicio crítico y de la práctica constante de la libertad de expresión, “entendida no como la celebración anual para 'gorrearle' al gobernador o al presidente en turno un banquete y los refrescantes tragos, sino en su calidad de expresión del pensamiento que sabe interpretar la voz del pueblo" (La Voz del Sureste, 28 de junio de 1986).

En el festejo de 1987, regresaron las palabras, los abrazos, los diplomas y doscientos cincuenta mil pesos a cada galardonado.

Hasta entonces los festejos habían incluido solo a periodistas chiapanecos, pero la llegada de Isabel Arvide a la dirección de comunicación social abrió el abanico para que sus 
amigos, radicados en el Distrito Federal, tomaran días de descanso y de bohemia en Chiapas, de esta manera la celebración tendría resonancia nacional.

El jurado calificador —integrado por Edmundo Valadés, Prudencio Moscoso, Juan Cervera, Alejandro Aura, Eraclio Zepeda, Beatriz Espejo y Carmen Boullosa, entre otros- decidió que no solo se reconociera a los periodistas, sino también a los que se dedicaban a la creación literaria.

En la ceremonia de entrega de los reconocimientos y de cuatro millones de pesos a cada premiado, realizada en la Casa de cultura de Comitán, el gobernador reclamó crítica inteligente "y no solo la descripción fría, para encontrar las soluciones más coherentes y acertadas a los problemas de la sociedad". Siguieron después palabras de elogio, y la imposición de una medalla al mandatario — por parte de la coordinadora de comunicación social- en reconocimiento a su irrestricto respeto de la libertad de expresión.

El festejo habría sido un éxito completo para el gobierno si Rosa Rojas, reportera de La Jornada, al recibir un reconocimiento no acusara a Absalón Castellanos Domínguez de asesino y represor de indígenas y campesinos chiapanecos.

En ese momento, los asistentes guardaron un profundo silencio, mientras que el gobernador y su coordinadora de comunicación social intercambiaban miradas de nerviosismo. 
Las declaraciones de Rosa Rojas no aparecieron en ningún periódico de circulación estatal, por la estrecha dependencia que tenían todas las publicaciones con el gobierno del estado, por lo que tuvo que ser ella, reportera de un medio nacional, la denunciante de esta realidad ocultada en Chiapas.

\section{EL PRIMER CUADRO DE LA CIUDAD, PROVEEDOR DE INFORMACIÓN PERIODÍSTICA}

Un reportero tuxtleco de los ochenta no tenía que recorrer más de cinco calles para encontrarse con sus fuentes de información y de financiación.

Su centro de operaciones - por la capacidad de generar recursos subterráneos entre presidentes municipales, diputados y aspirantes diversos a puestos de elección popularera el Congreso del estado. Le seguía la presidencia municipal, que compartía espacios de la plaza cívica con el palacio de gobierno y los edificios federales, que albergaban las delegaciones de Secofi, Reforma Agraria, Correos y Telégrafos.

A un costado, despachaban los líderes de CNC, quienes se habían acostumbrado a tener en la nómina a varios periodistas, a cambio de algunas líneas publicitarias.

La Procuraduría de justicia del estado, que se encontraba a una cuadra del Congreso estatal, era proveedora de la materia prima que reclamaban los lectores ocasionales, 
conformada principalmente por homicidios, demandas y escándalos diversos de gente normalmente de bajos recursos- que se habían ganado sus cinco segundos de fama en la contraportada de los periódicos tuxtlecos.

La rutina no era muy diferente en Tapachula, ni en San Cristóbal ni Comitán, donde los reporteros se reunían en el parque central para revisar los contenidos de los periódicos, y trazar sus rutas, de sur a norte, de oriente a poniente, sin tener que andar más de quinientos pasos en dichos rumbos.

Bastaba la presidencia municipal, alguna delegación, que estaban siempre en el centro de las poblaciones, para obtener la información política del día.

La nota roja, generada en las agencias del ministerio público, la cubrían los únicos periodistas especializados de entonces: los reporteros de policía.

"A diferencia de lo que sucedía en la ciudad de México, en Chiapas los reporteros no tenían asignadas sus fuentes: cubrían lo primero que encontraran en el primer cuadro de la ciudad. Nada más", refiere Daniel Flores Meneses, director de Prensa, Radio y Televisión de 1983 a 1985 (entrevista, 14 de noviembre de 2005).

Los periódicos, sobre todo de Tuxtla y de Tapachula, aprovechaban la lejanía de la ciudad de México para presumir del servicio de diversas agencias de noticias, sin que estuvieran abonados al servicio. La agencia PUL era, en repetidas ocasiones, mencionada 
dentro de las agencias de mayor presencia, seguida por AFP, Interamerican Press Service,

Servicios Editoriales CSE, Servicio Británico de Información, Agencia Universal de Noticias, Cemex, Fonel, AP y Notimex.

El producto más publicado era, sin embargo, el boletín, que se confeccionaba en las oficinas de Comunicación Social del Gobierno del Estado.

"Lo que enviáramos a los periódicos, los directores lo publicaban, y hasta en primera plana. No tenían el mayor empacho en hacerlo o, siquiera, poner que era el boletín. Ante el florecimiento de los comunicados y la ausencia de la crítica, el gobierno estaba feliz", comenta Flores Meneses (ibídem).

La uniformidad de la información se hacía tan sorprendente y sin recato que molestó a Isabel Arvide, quien en un afán de que los periódicos contrataran reporteros prohibió el envío de comunicados de prensa.

Julio Serrano Castillejos en su columna "De dulce, de chile y de manteca", hizo un llamado sobre la pobreza informativa de los periódicos:

La gente sigue en espera de una prensa crítica en las cuestiones de fondo, sin entreguismo, sin la sobrevivencia del facturismo y comprometida con el conglomerado y no exclusivamente con los hombres de la cosa pública. Por ejemplo, ¿se ha analizado a fondo lo conflictivo de los precios de garantía del maíz? ¿Qué opinión les merece a los columnistas locales lo manifestado por los representantes de la Liga de Comunidades Agrarias de la CNC y de la Central Campesina 
Independiente, en el sentido de que los precios autorizados a dicho grano no son los suficientes para hacer producir a la tierra?

Una prensa pobremente informativa y en la escala del cero por lo que hace a la crítica sana y objetiva, estará limitada siempre por su falta de imaginación y condenada a la atomización de veinte periódicos semidiarios — pues los lunes ni las gallinas ponen—, con un índice de lectores sumamente bajo (La Voz del Sureste, 28 de junio de 1986).

El tema indígena, que debería estar presente en las publicaciones, solo tenía su espacio asegurado en Tiempo, de Amado Avendaño, un periódico que también destinó páginas a los destrozos que realizaba en la selva Lacandona Jorge Martínez Rosillo, un protegido del gobernador.

Las posibilidades de practicar géneros periodísticos diferentes a la nota informativa, el artículo o la columna, eran prácticamente nulas, porque realizar una entrevista de semblanza, una crónica o un reportaje, requería de tiempo y de dinero, dos bienes muy escasos entre los reporteros, quienes tenían que cumplir diariamente con la entrega de tres notas. No era raro, por lo tanto, que se intercambiaran declaraciones, rumores o hallazgos, y que en esa cadena informativa se tergiversaran los hechos.

Las iniciativas por ensayar un periodismo diferente provinieron de reporteros formados, en su mayoría, en aulas universitarias. Las revistas Perfil del Sureste, Bonampak, Ámbar, y el diario El Observador de la Frontera Sur, representaron esfuerzos por construir otra racionalidad de ver la prensa, a sus actores y a su escasísimo público. 


\section{UPD Y LAS ORGANIZACIONES PERIODÍSTICAS}

Los diferentes intereses de directores, reporteros, corresponsales y columnistas conllevaron a la existencia de varias organizaciones de periodistas.

La más antigua, la Unión de Periódicos Diarios, creada en 1962 por dueños de periódicos, tenía una presencia cada vez más debilitada, por lo que sus integrantes la desaparecieron, y en su lugar fundaron, en 1984, la Asociación de Editores de Chiapas (Adech), dependiente de la Asociación Mexicana de Editores. Ahí tuvieron cabida los dueños de El Día, El Heraldo, Novedades de Chiapas, La Tarde, La Tribuna y Cuarto Poder.

La Unión de Corresponsales Nacionales de Chiapas (Unconach), fundada en octubre de 1983, aglutinó a periodistas tuxtlecos que escribían para diarios nacionales, como Candelaria Rodríguez Sosa (Proceso); Amet Flores Meneses (El Día); Juan de Dios Moreno Valle (El Sol de México); Eduardo Moreno Castellanos (Novedades); José Rosemberg Ovilla Martínez (El Universal); Francisco Ramírez Solís (El Heraldo de México); Leticia Hernández Montoya (Excélsior); Yolanda Pardo Plata (Canal 13), y Juan Balboa Cuesta (Unomásuno y Notimex).

Los reporteros y columnistas estaban divididos en tres organizaciones: La Asociación de Reporteros y Redactores (ARRPRECH), Prensa Chiapas, el Club de Periodistas, y la Unión de Periodistas Democráticos. 
ARRPRECH era la que congregaba el mayor número de afiliados, tanto de Tuxtla como de Tapachula y de diversos lugares de la entidad. Era una organización que no discriminaba el ingreso de ninguna persona, por lo que resultaba frecuente que, individuos ajenos al oficio, utilizaran sus siglas para medrar y amenazar a funcionarios municipales.

A finales de 1983 "conquistaron” — así lo presumían— el pago de aguinaldo, por parte del gobierno estatal, para todos los reporteros afiliados a esta organización (Cuarto Poder, 11 de enero de 1984).

El Club de Periodistas tenía un perfil conservador. Sus miembros lo constituían informadores conocidos, con larga andadura, pero leales al sistema priísta que los había engendrado. Llegaron, incluso, a proponer candidatos a diputados por el PRI. Debido a desavenencias entre sus integrantes desapareció en 1986.

Los encuentros de periodistas chiapanecos que organizó el Club fomentaron el intercambio de experiencias entre los informadores establecidos en Chiapas y los que laboraban en el Distrito Federal.

La Unión de Periodistas Democráticos, delegación Chiapas, canalizó las inquietudes de la nueva generación de informadores: organizó también encuentros de periodistas, en coordinación con el Programa Cultural de las Fronteras; marchó en protesta por la 
represión a sus miembros; exigió el pago de salarios mínimos profesionales para sus afiliados y, lo más importante, propició la discusión, el debate y la concienciación de su actividad. Sus integrantes fueron autocríticos y asumieron compromisos y responsabilidades para transformar la forma y el fondo del periodismo que les había tocado desempeñar.

UPD propició un cambio de actitud de los periodistas hacia los políticos y la sociedad. Fue la primera sacudida que sufrieron en sus valores y su actuación: deseaban no solo manejar con profesionalismo los diversos géneros del periodismo, sino hacerlo con orgullo y respeto al oficio.

Entendieron que su mínima incidencia en la sociedad se debía a la prepotencia, al chantaje, a su imbricación con el poder, y eso debía cambiar si se deseaba reconquistar espacios de credibilidad entre los ciudadanos. Sería un proceso lento de transformación, pero ya se había empezado a mirar el periodismo como un ejercicio crítico y de responsabilidad social.

\section{EL FINAL DE UN GOBIERNO “BUENO”}

Al director de La Tribuna, José Luis Cancino Guillén, le gustaba externar su hipótesis de los gobiernos estatales. Según él, había un gobernador "bueno" para los editores chiapanecos y otro "malo". Lo ejemplificaba de esta manera: Efraín Aranda Osorio repartió dinero a todos los periodistas; el siguiente, Samuel León Brindis, cerró con llave 
la tesorería, pero José Castillo Tielemans la abrió de nueva cuenta para los periodistas. Tocó después la austeridad de Manuel Velasco Suárez, que fue reemplazada por la generosidad de Jorge de la Vega Domínguez. Salomón González Blanco, sumido en la senilidad, hizo lo único que sabía hacer: guardar el dinero, un dinero que a la llegada de Juan Sabines encontró mejores bolsillos, muchos de los cuales eran de periodistas.

Absalón Castellanos debía ser un gobernador "malo" para los editores, pero no fue así: su gobierno fue la expresión del despilfarro hacia la prensa, que provocó, entre otros efectos, la multiplicación de publicaciones y de periodistas. Al depender del erario no fue posible la constitución de órganos independientes, sino dependientes —en su línea editorial y económica— del gobierno estatal.

Una prensa sometida a la voluntad oficial, como estaba la prensa chiapaneca, evitó que el gobierno aplicara medidas punitivas a los informadores, como se constata en este escrito.

Era una prensa libre, como diría Daniel Cossío Villegas, porque en el plano jurídico había una Ley de imprenta y una Constitución política que amparaban la libertad de imprenta, pero no hacía uso de su libertad por conveniencia económica, más que por represión oficial.

Las empresas informativas no presentaron un producto atractivo, crítico y orientador de la realidad nacional y estatal. No solo no informaban, sino que desinformaban de lo 
acontecía en el entorno político, social, cultural y educativo. Fue una prensa construida para medrar, ofender, extorsionar y desinformar a los ciudadanos.

Una prensa así, salpicada apenas por algunas publicaciones independientes, no propició la creación de un público lector amplio y exigente, en un Chiapas con un alto índice de analfabetismo y pobreza extrema, lo cual dificultaba doblemente la conformación de una clase lectora ciudadana.

Los lectores habituales eran el gobernador y los políticos de alto rango, para ellos se escribía en los periódicos, sobre todo para buscar su aquiescencia en la búsqueda de subvenciones, chayos y peines.

La generosidad de los gobernantes invitó a nuevos personajes para que se involucraran en el periodismo, porque la táctica era demasiada elemental, pues solo bastaba publicar elogios y fotografías del gobernador para poder facturar las planas en las oficinas de comunicación social.

Por eso, el concierto de voces de los periodistas fue de sumisión en torno a las acciones del gobierno de Absalón Castellanos Domínguez, y solo fueron notas aisladas, en medios nacionales principalmente, las que señalaran los errores del gobernador, le cuestionaran y a veces enjuiciaran. 
El ambiente político que les tocó vivir a estos periódicos fue de sacralización del presidente de la república, en primerísimo lugar; y en un segundo lugar, de gobernadores, senadores y diputados.

Fue una sociedad rendida al sistema político, sin espacios para el disenso ni la opinión libre. Y la prensa, como producto de esa sociedad, no podía presentar propuestas diferentes, sino, en todo caso, reflejar esos mecanismos de cortejo, de servicio y de complacencia hacia el poder. 


\section{BIBLIOGRAFÍA}

Hemerografía

Ámbar Semanal. Tuxtla Gutiérrez, 1989-1991.

Aquí. Tuxtla Gutiérrez, 1988-1991.

Bonampak (revista). Tuxtla Gutiérrez, 1985.

Caretas. Tuxtla Gutiérrez, 1987.

Cuarto Poder. Tuxtla Gutiérrez, 1975-1988.

El Chiapaneco. San Cristóbal de Las Casas, 1983.

Chiapas Hoy. Tuxtla Gutiérrez, 1984.

Chiapas Libre. Tuxtla Gutiérrez, 1981-1988.

El Día. Tuxtla Gutiérrez, 1981-1988.

Es! Diario Popular. Tuxtla Gutiérrez, 1982-1988.

El Heraldo. Tuxtla Gutiérrez, 1982-1988.

Número Uno. Tuxtla Gutiérrez, 1981-1988.

El Observador de la Frontera Sur. Tuxtla Gutiérrez, 1988-2000.

El Orbe. Tapachula, 1977-1988.

El Sol de Chiapas. Tuxtla Gutiérrez, 1982-1988.

La Voz del Sureste. México, 1982-1988.

Entrevistas

Acevedo, Carlos. 1 de febrero de 2006, Tuxtla Gutiérrez.

Arévalo Martínez, Armando. 15 de enero de 2006, Tuxtla Gutiérrez.

Flores Meneses, Daniel. 14 de noviembre de 2006, Tuxtla Gutiérrez.

Ortega López, Romeo. 28 de febrero de 2006, Tuxtla Gutiérrez.

Publicaciones

Bohman, Karin, 2001, Medios de comunicación y sistemas informativos en México. Alianza Editorial, México.

García Cuéllar, Enrique A., 2004, Cuando el imperio de la ley llegó a Chiapas. Patrocinio y su paso por el gobierno. Edamex, México, D.F.

García Mendoza, Higinio, 1986, Análisis de un modelo regional de televisión educativa. Tesis de licenciatura. Universidad Veracruzana, Veracruz.

Martínez Mendoza, Sarelly, 2004, La prensa maniatada. El periodismo en Chiapas de 1827 a 1958. Gobierno del Estado de Chiapas-Fundación Manuel Buendía, México, D.F. 
Portela Alvarado, Ruperto, 1994, Desarrollo del ejercicio periodístico en Chiapas. Secys-Cobach-Spaunach. Tuxtla Gutiérrez.

Scherer García, Julio, y Carlos Monsiváis, 2003, Tiempo de saber. Prensa y poder en México. Aguilar, México.

Palacios, Óscar, 1988, Me lo dijo Gervasio (anecdotario). Ediciones Yashalum, Tuxtla Gutiérrez.

Programa Cultural de las Fronteras. SEP, 1987, Primer foro de cultura contemporánea de la frontera sur. México, D. F.

Ruiseñor Esquinca, Carlos, 1994, El precio de la noticia. Crónica de medio siglo 19441994. Editorial Diálogo, Tuxtla Gutiérrez, Chiapas.

\footnotetext{
Notas

${ }^{1}$ Roberto Mancilla presentó otra versión de la frase, pero que en nada cambia el sentido de las declaraciones de Absalón Castellanos: “ "No sé qué tengo pero cada vez que estoy frente a los periodistas tiemblo', es la expresión original del señor gobernador. Por mi mente pasa con la velocidad del rayo y la expresión: será por los sablazos" (La Voz del Sureste, 8 de junio de 1984).

${ }^{2}$ De las setenta y cinco publicaciones chiapanecas de finales de 1988, cincuenta se editaban en Tuxtla. La lista era encabezaba alfabéticamente por Atisbos, continuaban Chiapas Libre, Cuarto Poder, Es! Diario Popular, El Debate, El Día, El Heraldo, El Observador de la Frontera Sur, Perfil, El Periódico, El Planeta de Chiapas, El Sol de Chiapas, Gaceta de Chiapas, La República en Chiapas, La Respuesta, La Tarde, La Tribuna, La Versión, La Voz del Sureste, Novedades de Chiapas, Número Uno, Signos, Semanario Plural, Combate, Confidencias, El Cascabel, Marcha, Hablemos, La Nueva Estrella de Oriente, Ámbar, Eco, La Verdad en Chiapas, Noticias de la Semana, Nueva Era, Panorama de Chiapas, Perfil del Sureste, Semanario Católico, Unión, Comunicándonos, Debate Nacional, Década, Diálogo, Gaceta, Guía Política, En Chiapas Caretas, Impactos, ICACH, Nueva Revista Chiapas, Torogoz y, finalmente, un título emblemático para retratar esos tiempos de alumbramiento permanente de periódicos: Otro Más. Tapachula era la segunda ciudad en importancia en cuanto al número de publicaciones. Ahí se editaban Diario del Sur, El Orbe, El Sol del Soconusco, Noticias de Chiapas, Sur de México, Uno más Dos, Extra, Pueblo, La Visión de Chiapas y Verdad. En ese listado, aparecía después San Cristóbal, con Tiempo, Avante, Nuestra Palabra y El Sur de Chiapas; Villaflores con El Dictamen y El Fraylescano; Arriaga con El Espectador y Primera Plana, y Tonalá, Expresión y La Prensa de la Costa. En otros municipios solo había una publicación, como Huixtla, donde se publicaba El Informador; Comitán: El Mundo; Pichucalco: Panorama; Cintalapa: Ecos del Valle; Motozintla: Labor Municipal, y en Yajalón, Nueva Generación. En el Distrito Federal, dos periodistas chiapanecos, Alfonso Morales Calvo y Héctor Ruiz León, hacían circular en la entidad las revistas México y La Palabra.
} 
${ }^{3}$ Con la expresión, "diecisiete desorientadas cabezas", el periodista se refería a los diecisiete diarios que para entonces se publicaban en Tuxtla: El Heraldo, Es! Diario Popular, La Tribuna, El Sol de Chiapas, La Voz del Sureste, Cuarto Poder, El Planeta, La República en Chiapas, El Día, Número Uno, Novedades de Chiapas, Atisbos, Últimas Noticias del Ahuizote, Seis A.M., Chiapas Libre, La Versión y La Tarde.

${ }^{4}$ De acuerdo con Fernando Castellanos, de la industria de la información vivían más de mil personas en Chiapas. Ahí trabajaban "linotipistas, prensistas, ayudantes de linotipistas, barrenderos, recepcionistas y, como una cascada, llega el dinero a una clase más marginada que encuentra forma de sobrevivir, como es el papelero" (El Planeta, 8 de junio de 1984).

${ }^{5}$ El salario mínimo de 1983 fue en el centro de Chiapas de doscientos pesos, y en el Soconusco, veinticinco pesos más. Aunque el burócrata ganaba trescientos ochenta pesos diarios, no se comparaba con lo que cobraba de dieta un diputado: diez mil pesos cada día.

${ }^{6}$ En la celebración de 7 de junio de 1988, realizada en Comitán, Isabel Arvide invitó a más de cuarenta periodistas de la ciudad de México; gastó un presupuesto de cien millones de pesos, y entregó premios de cuatro millones de pesos a los periodistas, cuando en el Distrito Federal era de tres millones (Diario del Sur, 8, 9 y 10 de junio de 1988).

${ }^{7}$ Diario del Sur dedicó a Isabel Arvide una semana de titulares a ocho columnas en 1988: "Isabel Arvide Limón debe salir de Chiapas" (9 de junio); "La Chabelona Arvide, periodista de pacota" (10 de junio); "Alocadas declaraciones de Isabel Arbide" (11 de junio); "Chabela Arvide, auténtica enemiga de ACD" (12 de junio); "La Arvide corrida como periodista del DF" (14 de junio).

${ }^{8}$ El delegado de Servicios Migratorios de Tapachula, Francisco Javier Salazar Salazar, intentó detener en El Sur de México a los reporteros Bernardo Arriaga Ancheyta y Rafael Victorio Ruiz, por críticas a su persona, pero al no encontrarlos llevó preso al formador del periódico (Diario del Sur, 21 de febrero de 1984). Ocho meses después, Eduardo Delía, comandante de la dirección de investigaciones políticas y sociales de Tapachula, se introdujo a las oficinas del Diario del Sur y amenazó al único que encontró, al corrector de estilo (Diario del Sur, 30 de octubre de 1984). Un mes antes, el reportero de El Planeta de Chiapas, Humberto Dimas Pérez, había sido golpeado y amenazado de muerte por el comandante de Seguridad Pública, Guillermo Mendoza (El Planeta, 1 de septiembre de 1984). Joel Solar, corresponsal de Unomásuno; Saúl Cruz, de la revista Alarma!, y Rodolfo Sol, de Excélsior también habían sido vejados por agentes de migración. 